\title{
DOPPLER BROADENING AND POSITRON LIFETIME MEASUREMENTS OF WELL-CHARACTERIZED SANDSTONE AND LIMESTONE ROCKS .
}

\author{
J.M. Urban, C.A. Quarles \\ Texas Christian University, Physics Dept., Fort Worth, TX 76129, USA \\ and G.N. Salaita \\ Chevron Petroleum Technology Co., Box 446, LaHabra, CA 90633-0446, USA
}

We measured the $S$ parameter for samples of well-characterized rocks. Some samples were cleaned while others contained natural hydrocarbons. We also saturated some samples with oil. Preliminary results show a difference in the $S$ parameter for sandstone and limestone samples. There is also a significant difference between samples when clean and when containing natural hydrocarbons or when saturated with light oil. We also measured the lifetime spectrum for the same samples in dry, fresh water-saturated, and brine-saturated condition. The observed lifetime spectra could be described with two or three components. While a detailed understanding of the physical processes responsible for the lifetime spectra is still under study, several interesting results have been obtained. The average lifetime is correlated with the $S$ parameter. The porosity of the samples is correlated with the intensity of the third lifetime component. The average lifetime, as well as the second lifetime component, is systematically longer in the sandstone than limestone samples, and in water or brine-saturated samples. The intensity of the third lifetime component is generally larger in the water or brine-saturated samples.

PACS numbers: 91.60.-x, 78.70.Bj, 71.60.+z, 61.80.Fe

\section{Introduction}

Over the years, positron annihilation spectroscopy (PAS) has been applied to a wide variety of materials. However, to our knowledge, although there have been some studies of minerals [1-4], PAS has not previously been applied to the study of rocks. This research was undertaken to investigate what, if anything, could be learned about heterogeneous materials like rocks using the PAS technique. It is hoped that what is learned in the laboratory studies of well-characterized rock samples might eventually be developed into an application for use in a well logging tool. Two PAS techniques have been used: Doppler broadening of the annihilation radiation or $S$ parameter, and positron or positronium lifetime spectroscopy. The 
$S$ parameter is defined as the ratio of the number of photons in the central region of the $511 \mathrm{keV}$ line (within about one $\mathrm{keV}$ of $511 \mathrm{keV}$ ) to the total number of photons in the peak. As we will show, PAS generally distinguishes sandstones from limestones, and whether pores in the rocks are empty or filled with water, brine or hydrocarbons. Detailed analysis can provide some information about both macro- and micro-porosity of the rock.

\section{Experimental details}

Previous work with silica gels had shown a correlation of the ortho-Ps lifetime with the pore size $[5,6]$. Therefore we began our studies to see if there was

TABLE I Composition of samples. The major constituents are given as weight \% from $\mathrm{X}$-ray fluorescence measurements. Values less than $0.1 \%$ are not listed. CRRS refers to Carbonate Reservoir Rock Samples. Significant components not listed in table: CRRS\#8, 3.4\% $\mathrm{Sr}$ content; Boise Sandstone, $3.6 \% \mathrm{Na}_{2} \mathrm{O}$ and $3.5 \% \mathrm{~K}_{2} \mathrm{O}$; Berea and Navajo Sandstone, $0.9 \% \mathrm{~K}_{2} \mathrm{O}$.

\begin{tabular}{l|c|c|c|c|c|c|c|c}
\hline \multicolumn{1}{c|}{ Sample } & $\mathrm{H}_{2} \mathrm{O}$ & $\mathrm{CO}_{2}$ & $\mathrm{SiO}_{2}$ & $\mathrm{Al}_{2} \mathrm{O}_{3}$ & $\mathrm{CaO}$ & $\mathrm{MgO}$ & $\mathrm{Fe}_{2} \mathrm{O}_{3}$ & $\mathrm{SO}_{3}$ \\
\hline Boise Sandstone & 0.9 & 0.1 & 75.5 & 12.1 & 1.4 & 0.3 & 1.2 & 0.9 \\
Berea Sandstone & 0.8 & 0.9 & 90.3 & 3.2 & 0.6 & 0.4 & 1.1 & 1.2 \\
Navaho Sandstone & 0.3 & 0.2 & 95.6 & 1.4 & 0.3 & - & - & 1.1 \\
Potsdam Sandstone & $\mathrm{na}^{*}$ & $\mathrm{na}$ & $\mathrm{na}$ & $\mathrm{na}$ & $\mathrm{na}$ & $\mathrm{na}$ & $\mathrm{na}$ & $\mathrm{na}$ \\
Spergen Limestone & 0.5 & 43.6 & 1.1 & 0.1 & 55.0 & 0.6 & 0.1 & - \\
Vermont Marble & 0.1 & 42.7 & 0.4 & - & 54.9 & 0.3 & - & 1.6 \\
Yule Marble & 0.1 & 43.9 & 0.3 & - & 55.1 & 0.3 & - & 0.2 \\
Quadrant Quartzite & $\mathrm{na}$ & $\mathrm{na}$ & $\mathrm{na}$ & $\mathrm{na}$ & $\mathrm{na}$ & $\mathrm{na}$ & $\mathrm{na}$ & $\mathrm{na}$ \\
Anhydrite & 0.2 & 0.2 & 0.2 & - & 42.6 & 0.1 & 0.1 & 56.4 \\
Lockport Dolomite & 0.1 & 22.3 & 48.8 & 0.6 & 15.8 & 11.1 & 0.2 & 0.8 \\
CRRS \#2 & 0.3 & 41.9 & 0.2 & - & 51.2 & 4.4 & - & 2.2 \\
CRRS \#5 & 0.3 & 37.2 & 0.4 & - & 51.4 & 1.0 & - & 6.2 \\
CRRS \#8 & 0.4 & 38.6 & 0.1 & - & 46.9 & 0.5 & - & 0.9 \\
CRRS \#13 & 0.6 & 46.3 & 0.3 & 0.1 & 34.1 & 19.6 & - & 0.2 \\
CRRS \#109 & 0.2 & 43.8 & 0.4 & - & 53.7 & 0.4 & - & - \\
CRRS \#103 & 0.4 & 46.8 & 0.5 & - & 46.8 & 6.7 & 1.5 & - \\
CRRS \#104 & 0.4 & 44.3 & 0.7 & - & 30.6 & 18.1 & 5.1 & - \\
CRRS \#108 & 0.3 & 43.6 & 0.5 & - & 53.3 & 0.9 & - & - \\
\hline
\end{tabular}

* na = not available, since these samples were not analyzed for composition.

They are included in Table since they were used for positron measurements. 
some correlation of porosity with positronium lifetime or intensity. We selected samples initially from both sandstone and limestone rocks whose composition had been well-characterized. Table I lists the samples studied and their major constituents. The sample composition analysis was carried out by X-ray fluorescence techniques by Xray Assay Laboratories. Porosity measurements for some samples were provided by Chevron, and some were made at TCU by measuring the weight gain after soaking the sample in water. The $\mathrm{Na}-22$ source $(50 \mu \mathrm{Ci})$ was deposited as $\mathrm{NaCl}$ on a $1 \mathrm{mg} / \mathrm{cm}^{2}$ kapton film, covered with an identical film, and sealed with epoxy. For some of the $S$ parameter runs, a weaker source $(10 \mu \mathrm{Ci})$ was used where the $\mathrm{NaCl}$ was deposited between two $2 \mathrm{mg} / \mathrm{cm}^{2}$ nickel foils and sealed by electron beam welding.

The apparatus for the $S$ parameter measurements is typical. A high purity germanium solid state detector views the sample in an arrangement with the source sandwiched between two pieces of rock sample. We have used a Canberra or a Princeton Gammatech $10 \mathrm{~mm}$ thick planar detector with a resolution of about $1.2 \mathrm{keV}$ at $511 \mathrm{keV}$, determined by observation of the $569 \mathrm{keV}$ gamma ray from a Bi-207 source. The signal from the detector is amplified and recorded in a multi-channel analyzer (MCA) and then sent to a PC computer. The results for the $S$ parameter are shown in Fig. 1.

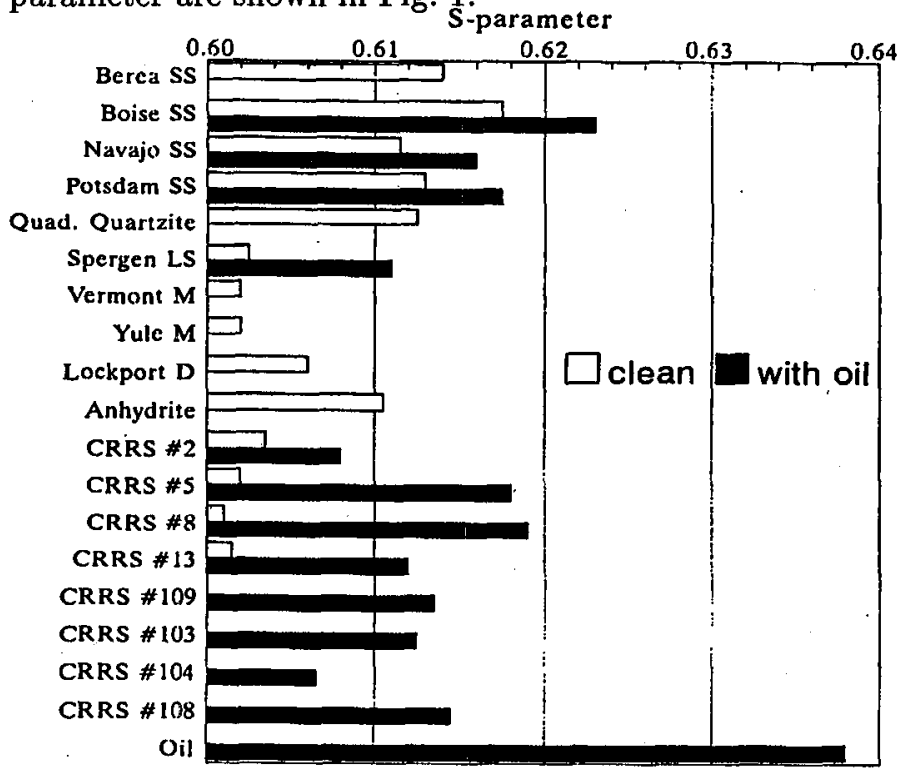

Fig. 1. Bar graph of the $S$ parameter. SS is sandstone, $\mathrm{M}$ is marble, and $\mathrm{D}$ is dolomite. CRRS is Carbonate Reservoir Rock Sample.

The experimental apparatus for the lifetime measurements is a typical fast timing setup. The Na-22 source is sandwiched between two pieces of the rock sample and placed in either a simple closed stainless cup or in a stainless vacuum cell. The rock samples are 1 inch diameter disks, $1 / 8$ or $1 / 4$ inch thick. The detectors are Hamamatsu H3168 photomultipliers coupled to plastic scintillator. The output 
TABLE, II

Lifetime results for dry samples. The lifetime spectra were fitted to three lifetime components with the shortest lifetime fixed at 123 picoseconds (ps). The statistical errors are shown in parenthesis.

\begin{tabular}{l|l|l|l|c|c|c|c}
\hline \multicolumn{1}{c|}{ Sample } & $I_{1}[\%]$ & $\tau_{2}[\mathrm{ps}]$ & $I_{2}[\%]$ & $\tau_{3}[\mathrm{p} \mathrm{s}]$ & $I_{3}[\%]$ & $\langle\tau\rangle[\mathrm{ps}]$ & Por [\%] \\
\hline Boise Sandstone & $25(5)$ & $297(14)$ & $66(3)$ & $735(93)$ & $9.4(2.3)$ & 296 & 23.7 \\
Berea Sandstone & $18(2)$ & $277(9)$ & $77(2)$ & $694(147)$ & $4.9(2.3)$ & 264 & 18 \\
Navaho Sandstone & $21(1)$ & $283(4)$ & $78(1)$ & $910(5)$ & $1.5(0.3)$ & 260 & 6.3 \\
Potsdam Sandstone & $23(1)$ & $287(5)$ & $77(1)$ & - & 0 & 250 & 4.9 \\
Spergen Limestone & $27(6)$ & $249(12)$ & $73(4)$ & - & 0 & .216 & 12.7 \\
CRRS \#2 & $19(2)$ & $240(6)$ & $81(2)$ & - & 0 & 219 & 23.7 \\
CRRS \#5 & $26(1)$ & $264(2)$ & $74(1)$ & - & 0 & 228 & 18.9 \\
CRRS \#8 & $26(2)$ & $244(4)$ & $74(2)$ & - & 0 & 214 & 32 \\
CRRS \#13 & $25(8)$ & $230(12)$ & $75(5)$ & - & 0 & 206 & 16.2 \\
Yule Marble & $9(3)$ & $221(6)$ & $91(3)$ & - & 0 & 212 & - \\
Quadrant Quartzite & $23(2)$ & $297(8)$ & $74(2)$ & $1010(122)$ & $3.0(1)$ & 278 & - \\
Anhydrite & $40(1)$ & $319(8)$ & $60(1)$ & - & 0 & 242 & 4 \\
Lockport Dolomite & $8(4)$ & $220(7)$ & $92(3)$ & - & 0 & 212 & -
\end{tabular}

TABLE III

Lifetime results for water-saturated samples.

\begin{tabular}{l|c|c|c|c|c|c|c}
\hline \multicolumn{1}{c|}{ Sample } & $I_{1}[\%]$ & $\tau_{2}[\mathrm{ps}]$ & $I_{2}[\%]$ & $\tau_{3}[\mathrm{p} \mathrm{s}]$ & $I_{3}[\%]$ & $(\tau)[\mathrm{ps}]$ & Por [\%] \\
\hline Boise Sandstone & $26(1)$ & $334(5)$ & $67(1)$ & $1235(86)$ & $7.2(0.5)$ & 344 & 23.7 \\
Berea Sandstone & $26(1)$ & $301(2)$ & $71(1)$ & $1471(150)$ & $3.3(0.4)$ & 295 & 18 \\
Navaho Sandstone & $21(1)$ & $291(3)$ & $76(1)$ & $1340(123)$ & $3.3(0.3)$ & 291 & 6.3 \\
Potsdam Sandstone & $23(2)$ & $291(4)$ & $75(1)$ & $1424(66)$ & $1.7(0.3)$ & 272 & 4.9 \\
Spergen Limestone & $29(2)$ & $260(2)$ & $69(2)$ & $1409(116)$ & $2.5(0.2)$ & 249 & 12.7 \\
CRRS \#2 & $29(1)$ & $262(3)$ & $67(1)$ & $1490(43)$ & $3.8(0.2)$ & 269 & 23.7 \\
CRRS \#5 & $23(2)$ & $264(4)$ & $74(1)$ & $1344(69)$ & $2.8(0.3)$ & 262 & 18.9 \\
CRRS \#8 & $29(2)$ & $264(4)$ & $67(2)$ & $1485(45)$ & $4.0(0.2)$ & 273 & 32 \\
CRRS \#13 & $30(1)$ & $243(3)$ & $68(1)$ & $1083(49)$ & $2.2(0.3)$ & 226 & 16.2
\end{tabular}

Lifetime results for brine-saturated samples.

TABLE IV

\begin{tabular}{l|c|c|c|c|c|c|c}
\hline \hline \multicolumn{1}{c|}{ Sample } & $I_{1}[\%]$ & $\tau_{2}[\mathrm{ps}]$ & $I_{2}[\%]$ & $\tau_{3}[\mathrm{p} \mathrm{s}]$ & $I_{3}[\%]$ & $\langle\tau\rangle[\mathrm{ps}]$ & Por [\%] \\
\hline Boise Sandstone & $29(4)$ & $330(8)$ & $65(4)$ & $1117(61)$ & $5.9(0.7)$ & 317 & 23.7 \\
Berea Sandstone & $22(1)$ & $294(4)$ & $75(1)$ & $1237(10)$ & $3.0(0.3)$ & 285 & 18 \\
Navaho Sandstone & $21(1)$ & $287(3)$ & $77(1)$ & $1040(75)$ & $2.1(0.4)$ & 270 & 6.3 \\
Potsdam Sandstone & $21(1)$ & $288(5)$ & $77(1)$ & $1516(107)$ & $1.9(0.3)$ & 277 & 4.9 \\
Spergen Limestone & $30(1)$ & $259(3)$ & $68(1)$ & $1397(21)$ & $1.7(0.2)$ & 238 & 12.7 \\
CRRS \#2 & $26(1)$ & $254(3)$ & $72(1)$ & $1410(54)$ & $2.0(0.2)$ & 243 & 23.7 \\
CRRS \#5 & $28(1)$ & $272(3)$ & $70(1)$ & $1345(56)$ & $2.2(0.2)$ & 255 & 18.9 \\
CRRS \#8 & $33(1)$ & $268(2)$ & $65(2)$ & $1444(47)$ & $2.2(0.1)$ & 247 & 32 \\
CRRS \#13 & $33(1)$ & $249(3)$ & $66(5)$ & $1254(59)$ & $1.2(0.2)$ & 220 & 16.2
\end{tabular}

signals from the photomultipliers are fed to constant fraction differential discriminators (Ortec model 583). The TAC (time-to-analogue converter) output for each coincident event is recorded in a MCA. The data from the MCA is readout to a PC computer. Source corrections have been made by measuring the spectrum for a pure, annealed nickel or copper sample [7]. While the source correction is small, it is significant in determining the intensity of the long lifetime component in the present data. The positron lifetime spectra presented here have been analyzed with PATFIT [8]. The apparatus was tested with the lifetime spectrum of a Bi-207 source fit to the known single lifetime convoluted with a Gaussian resolution function with a width of 230 picoseconds. 
Lifetime spectra have been taken for samples listed in Tabs. II-IV under dry, fresh water-saturated, and brine-saturated condition. The runs were made at room temperature. In several cases, the sample was placed under vacuum and then water vapor was introduced. Runs had from $3 \times 10^{5}$ to $10^{6}$ counts in the lifetime spectrum. Runs were typically 24 hours long using a Na-22 source of $\approx 50 \mu \mathrm{Ci}$ in a close geometry which maximized the coincidence rate for the detectors used. Over the course of this work, over 250 separate lifetime runs have been made. The crrors shown in parenthesis are statistical.

The data have been analyzed in several ways. Generally, an assumption of three lifetimes has been sufficient to obtain a good fit to the data. In several cases, particularly the dry limestones, a good fit was obtained with the assumption of only two lifetimes instead of three. We have found better stability and consistency from run to run with the PATFIT program if the fit is constrained by fixing the shortest lifetime. While fixing the shortest lifetime in the range $100 \mathrm{~ns}$ to $150 \mathrm{~ns}$ yields essentially the same results, we present in Tabs. II-IV the results for an analysis in which three discrete lifetimes are assumed and the shortest, $\tau_{1}$, is held fixed at 123 picoseconds. This is not meant to imply that the shortest lifetime is due only to para-Ps, since there is not enough ortho-Ps evident for this to be the case; but the shortest lifetime contains mainly the annihilation events due to free positron annihilation.

\section{Discussion and interpretation of results}

The results for the $S$ parameter in Fig. 1 correlate with both lithology and with the condition of the sample. First, the $S$ parameter for limestones is systematically lower than for sandstones. Next, the $S$ parameter is generally larger when the sample is saturated with a light machine oil or contains natural hydrocarbons (c.g., Carbonate Reservoir Rock Samples, CRRS \#103-\#109). The increase in the $S$ parameter is larger for the limestone samples. The $S$ parameter for oil alone is larger than the values measured for the oil-saturated samples, suggesting that more positronium is formed in the liquid. However, the increase observed in the oil-saturated samples is not simply a weighted average for the dry fraction and for the liquid fraction of the sample. The presence of the oil can affect the pore surfaces, and alter positronium or positron trapping mechanisms. Nevertheless, the differences in the $S$ parameter may provide a new way to distinguish the lithology or the pore-saturation condition of a rock formation.

Now consider the lifetime results presented in Tabs. II-IV. First, the intensity, $I_{3}$, is zero for the dry limestone samples and the Potsdam sandstone sample. This indicates that no positronium is formed in these samples. The average values of $I_{1}$ and $I_{2}$ are found to agree, within errors, for dry sandstone and limestone samples. The water- or brine-soaked sandstones show no significant change in either $I_{1}$ or $I_{2}$, whereas for the water- and brine-soaked limestones, $I_{1}$ increases by about $3-5 \%$, while $I_{2}$ decreases correspondingly.

The a verage $\tau_{2}$ is $286 \pm 14$ picoseconds for dry sandstone and increases slightly to $300 \pm 20$ picoseconds for the water- or brine-soaked samples. The average $\tau_{2}$ for dry limestone is lower than sandstone, $245 \pm 14$ picoseconds, and increases slightly 


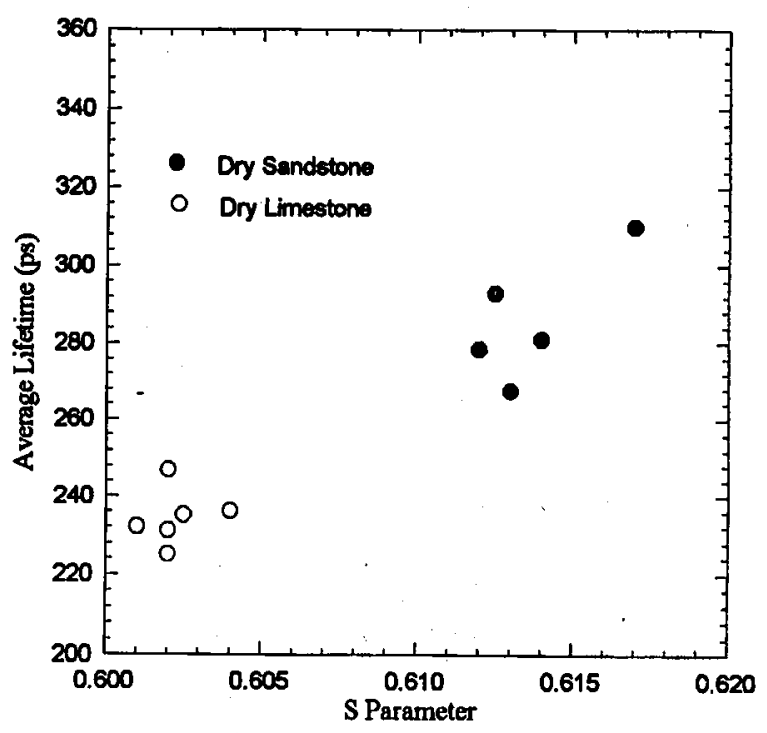

Fig. 2. Correlation of the average lifetime $\langle\tau\rangle$ with $S$ parameter for dry samples.

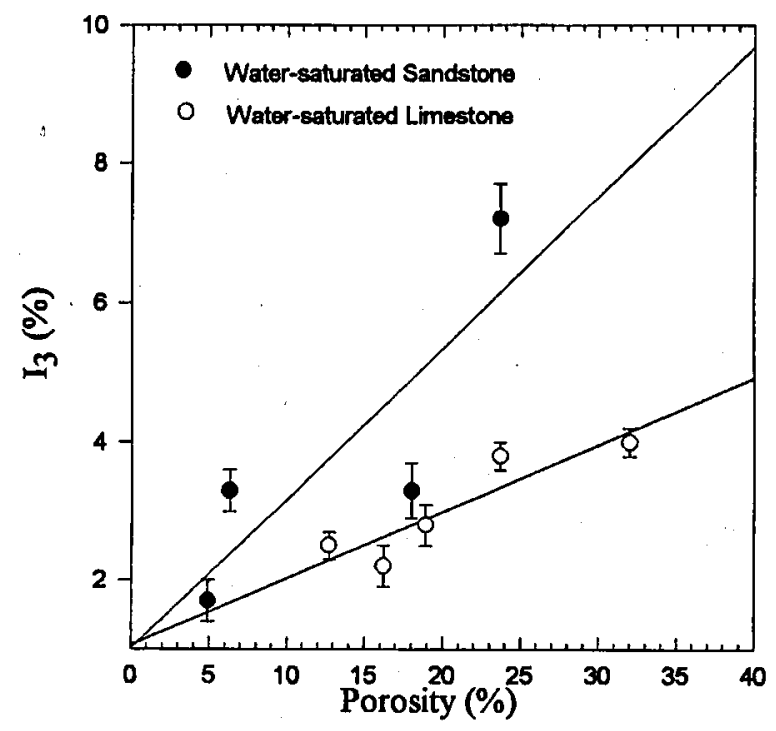

Fig. 3. Graph of the intensity of the long lifetime component $I_{3}(\%)$ versus porosity (\%) for water-saturated samples.

to $260 \pm 7$ picoseconds for the water- and brine-soaked case. We can assume that $\tau_{2}$ is due to free positron annihilation in the bulk material.

For water- or brine-soaked sandstone samples, the average $\tau_{3}$ is $1368 \pm 83 \mathrm{pi}$ coseconds and $1228 \pm 115$ picoseconds, respectively. The average $\tau_{3}$ for the water- 
and brine-soaked limestone samples $1362 \pm 69$ picoseconds and $1370 \pm 138$ picoseconds respectively, in good agreement with the water-soaked sandstone result.

The appearance of a third lifetime component or an increase in $\tau_{3}$ from the dry to water- or brine-soaked case is due to ortho-Ps formed in the water or brine that is trapped in the pores. However, the lifetime is shorter than the ortho-Ps lifetime of 1850 picoseconds for free water, indicating some effect of the pores on this lifetime. Further, we might expect that the lifetime would be shorter in brine due to the presence of the $\mathrm{NaCl}$ in the water, and this is observed at about the one standard deviation statistical level in the sandstone case but not in the limestone case.

Also shown for each sample in Tabs. II-IV is the weighted average lifetime $\langle\tau\rangle=\left(I_{1} \tau_{1}+I_{2} \tau_{2}+I_{3} \tau_{3}\right)$. This average lifetime is plotted versus the $S$ parameter for the dry samples in Fig. 2. As can be seen, the higher $S$ parameter correlates with a larger average lifetime for the sandstone and anhydrite samples, whereas the limestone and carbonate (CRRS) samples have both a lower $S$ parameter and a lower average lifetime.

In Fig. 3 we have plotted $I_{3}(\%)$ for the samples in water-soaked condition versus the macro-porosity (\%). There is a linear correlation of the intensity of the long lifetime component with the porosity for both sandstone and limestone samples. Thus the long lifetime component is mainly due to ortho-Ps formation in the water trapped in the pores of the sample.

\section{Summary and conclusions}

We have presented results from the first application of the PAS techniques to rocks. Our samples have included both sandstones and limestones in dry condition, and in some cases, with pores saturated with water, brine or oil. We have found variation of the $S$ parameter that depends both on lithology and on the condition of pore saturation. In the lifetime measurements we have observed that the spectra from the rocks can be fitted with the assumption of two or three discrete lifetimes. There is variation in both the average lifetime $\langle\tau\rangle$ and the intensity $I_{3}$ of the longest lifetime with both lithology and pore saturation. For the water- and brine-soaked samples, $I_{3}$ correlates with the customary macro-porosity. This indicates that the long lifetime component is due to ortho-Ps formed in the liquids in the pores. This is consistent with the larger $S$ parameter observed for the oil-soaked samples, but does not explain the difference in $S$ parameter between the dry sandstones and limestones.

Several areas of further study are desirable. Of course, we want to measure the $S$ parameter for water- and brine-saturated samples, as well as measure the lifetime for oil-saturated samples to complete the initial phase of the work reported here. It would be interesting to look for magnetic quenching effects on the $S$ parameter or lifetime spectra to determine whether positronium is formed differently in the sandstones and the limestones. Finally, it would be interesting to study a broader range of samples with a view toward establishing an $S$ parameter scale which could be useful in developing a well logging application of the PAS technique. 


\section{Acknowledgments}

We appreciate the help of Dr. Ching-yu Hsueh, Dr. Marc Dickinson, Dr. Nowell Donovan, Michael Hall, Angela Legoretta, Dr. Halim Lehtihet, Tammy Lehtihet, and Michael Murdock in various aspects of this experiment. We appreciate the helpful comments from Dr. T.W. Zerda, and Dr. B.N. Miller. We are especially grateful to Dr. J. Dryzek for comments and suggestions. The TCU authors gratefully acknowledge the support of the Welch Foundation, the TCU Research Fund, and the Chevron Petroleum Technology Co.

\section{References}

[1] J. Chojcan, M. Sachanbiński, Acta Phys. Pol. A 86, 267 (1993).

[2] M. Dimanchev, A. Shofan, T. Troev, J. Serna, Mater. Sci. Forum 105-110, 1545 (1992).

[3] F.H. Hsu, E.R. Vance, Phys. Chem. Miner. 6, 47 (1980).

[4] B.I. Zaslavskii, V.P. Shantarovich, M.S. Metsic, Phys. Scr. 34, 248 (1986).

[5] T.W. Zerda, G. Hoang, B. Miller, C.A. Quarles, G. Orcel, Mater. Res. Soc. Symp. Proc. 121, 653 (1988).

[6] B. Hopkins, C.A. Quarles, T.W. Zerda, Mater. Res. Soc. Symp. Proc. 180, 325 (1990).

[7] M. Bertolaccini, L. Zappa, Nuovo Cimento B LII, 487 (1967).

[8] P. Kirkegaard, M. Eldrup, O.E. Mogensen, N.J. Pedersen, Comp. Phys. Commun. 23, 307 (1981); and PATFIT (1989 Version), Tech. Rep. Ris $\varnothing-M-2740$, Ris $\varnothing$ Nat. Lab., Roskilde (Denmark) 1989. 